\title{
Exploration of Application Mode of the MOOC-based Distance Education Mode in Digital Illustration
}

\author{
http://dx.doi.org/10.3991/ijet.v11i09.6127 \\ Mei Zou \\ Huaihua University, Huaihua, China
}

\begin{abstract}
-with the continuous development of computer technology, online learning has also become a new trend. Noticeably, the MOOC-based distance education mode can meet students' demand for superior teaching resources and assist students to engage in independent study and teachers to change their classroom teaching mode. This paper started from the development status of MOOC and distance education to construct the MOOC platform and design the MOOC-based distance education mode. Then, a control experiment was adopted to explore the effect of applying such a mode in Digital Illustration and to analyze different teaching effects of the MOOC platform and existing online learning platforms. The conclusion offers certain reference for further promotion of the MOOC-based distance education mode.
\end{abstract}

Index Terms-Digital Illustration, distance education, MOOC

\section{INTRODUCTION}

The MOOC-based distance education mode has developed rapidly in recent years. MOOC refers to massive open online course. Numerous colleges meet the need of distance education and independent study through setting up their online learning platform and offering free courses on the platform [1]. MOOC is featured by abundant course resources, easy operation and extensive audiences. Students can engage in independent study according to their interests [2]. Distance education is an education mode in which teachers and students communicate through diversified multimedia forms. In modern distance education, courses are sent out from campus mainly through voice, video and other computer technologies, so as to achieve the objective of cross-school and crossregion education. The major characteristic of distance education lies in flexible learning place and form to conveniently expand teaching scale and reduce teaching cost [3].

The course of Digital Illustration is generated with the development of information technology. Its creation mainly depends on digital equipment and the use of materials from digital information [4]. In this age of teaching informatization, the integration of technology and art is the inevitable trend of historical evolution. Like traditional illustration, digital illustration must follow the esthetical principle of visual art and conform to people's visual habits and aesthetic needs. Convenient and efficient selection of diversified styles and paper characteristics is an important feature and advantage of digital illustration. As a new design fashion of art, digital illustration will be integrated with all kinds of art and enjoy a diversified development trend [5]. Thus, it is necessary and urgent to introduce the MOOC-based distance education mode in Digital Illustration teaching. High course quality and diversified forms of MOOC will undoubtedly facilitate optimization of teaching mode of the Digital Illustration course. In June 2013, the first batch of 120 resource sharing courses for Chinese universities was put on icourse. In 2014, MOOC of Chinese universities was launched online, attracting more than 1 million person-times of participants. Application of MOOC has brought a positive effect in computer, higher mathematics and finance courses, etc., and offers certain reference for practice and development of the MOOC-based distance education mode in Digital Illustration [6].

Chinese scholars have conducted many researches on MOOC and distance education. Liao proposed an online teaching mode based on the MOOC idea and carried out detailed analysis of the teaching mode centered by online teaching and multi-layer collaborative communication [7]. Some researchers took part in multiple courses of Coursera as online learners and summarized its teaching method in the aspect of course content organization, resource design, student-teacher interaction and diversified evaluation in combination of the forms and features of existing courses in China [8]. However, for current MOOC, video resources are recorded in most circumstances. After recording, video editing means is required to make MOOC courses for users. In addition, classification of knowledge points shown in teaching is subject to classification association. Thus, when users play MOOC through retrieval based on classification of knowledge points, some video content unrelated to the retrieval may be played, seriously affecting students' learning efficiency.

To solve the problem above, this study creatively proposed a method of editing videos of MOOC knowledge points. Besides, based on design of the MOOC distance education mode, it then investigated the teaching effect of Digital Illustration. The conclusion offers theoretical and statistical support for application of the MOOC-based distance education mode in Digital Illustration and other college courses.

\section{CONSTRUCtion OF THE MOOC PlatForm}

The MOOC platform was constructed by integration of the network, videos recorded by teachers, courseware, case studies and other teaching resources. Teachers can 
$\log$ in the platform to update content, publish information and arrange assignment. Meanwhile, students can achieve independent study with the platform [9]. Due to the strong openness of the MOOC platform, users can gain relevant course resources after registration. Teachers could guarantee integrity of teaching system through continuously adjusting learning contents for students and enrich students' practical ability with the latest cases [10]. The design of knowledge point- centered video editing based on MOOC is shown in figure 1.

\section{Design Of MOOC-BASED DistANCE EDUCATION MODE}

Specific teaching implementation scheme of the MOOC-based distance education mode is as follows:

\section{A. Teaching content design}

The teacher should complete the design of course outline, teaching process and interactive exchange before class. Firstly, overview of the course should be offered for students to clearly know the learning objective and make theri learning plan. Secondly, the teacher should also subdivide the teaching content according to different learning situations and achieve fragmentization of the knowledge system. The integration of fragments should be able to support objective of the course. Finally, students seize interactive exchange opportunities, ask questions and gain expansion of course knowledge.

\section{B. Teaching link design}

Design structure of teaching via the MOOC-based distance education mode is shown in figure 2 .

\section{1) Before-class video}

The teacher seeks superior teaching videos from MOOC and share them with students. Students complete acquistion of basic theoretical knowledge about Digital Illustration according to MOOC teaching videos specified by the teacher.

\section{2) Classroom teaching}

Classroom teaching includes question discussion and practice. Question discussion aims to solve common doubts of students. The teacher should create a free exchange situation for students and guide them to discuss.
This flexible way is used to preliminarily convey the difficult teaching points. Practice is the key part of classroom teaching. The teacher requires students to practice according to the teaching objective and the focus of students' questions.

\section{3) After-class interaction}

The teacher publishes summaries and supplements of the course content with via the MOOC platform after class. Students conclude and summarize the knowledge learned and correct the mistakes in practical operation.

\section{4) Assignment arrangement}

To further enhance the effect of classroom teaching, the teacher may arrange assignments and extracurricular expansion tasks on the MOOC platform. Assignment arrangement should be combined with the teaching content. Extracurricular expansion tasks aim to cultivate students' learning interest, train their practical ability, and improve construction of the professional knowledge system. Students can exchange through the MOOC platform and communicate online with the teacher within specific time periods.

\section{5) Assessment of students}

Under the MOOC-based distance education mode, teaching process is no longer limited to classroom time, making it necessary for the teacher to assess students in an all-round way. Targets of assessment involves degree of students' participation in teaching activities, records of applying the MOOC course platform and students' afterclass test scores.

\section{EXPERIMENT OF APPLYING THE MOOC-BASED Distance Education Mode In Digital ILLUSTRATION}

In the course of Digital Illustration, CG digital illustration is taught comprehensively from introduction to the stage of mastery. Its course content includes specilized courses of fine arts in colleges. Theory explanation, case analysis, complete process demonstration and training guidance are combined, with the mainstream CG drawing software used as the tool to systematically introduce digital illustration. Detailed application could be seen in figure 3 and figure 4 .

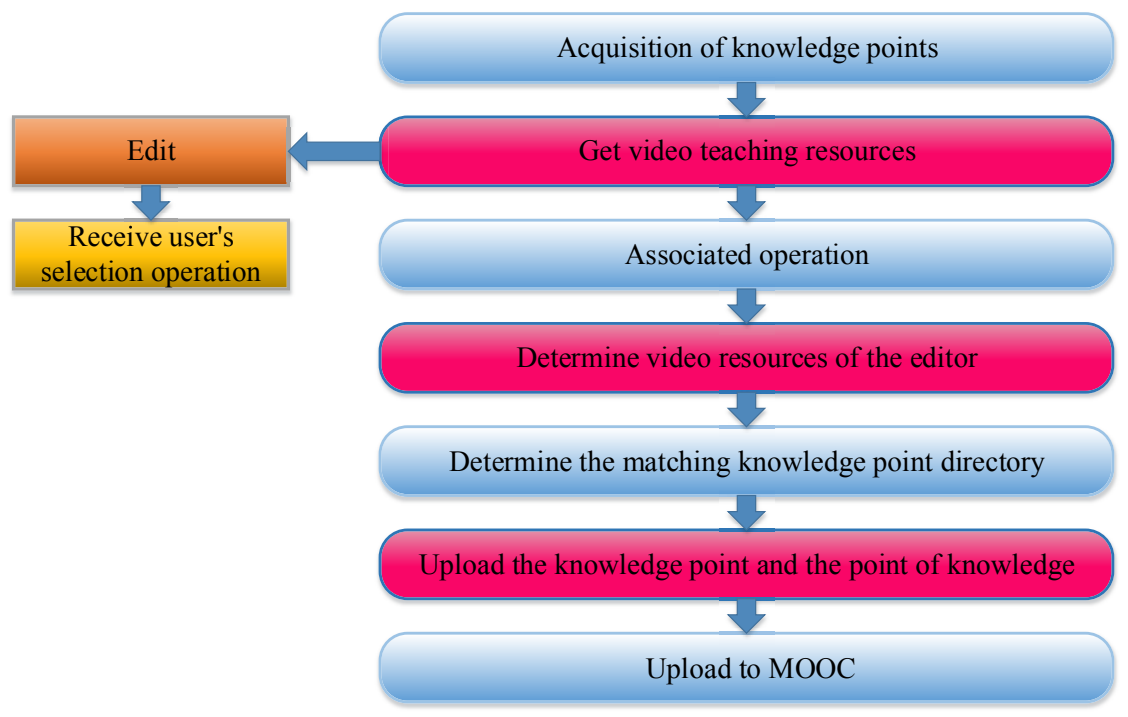

Figure 1. The design of knowledge point-centered video editing based on MOOC 


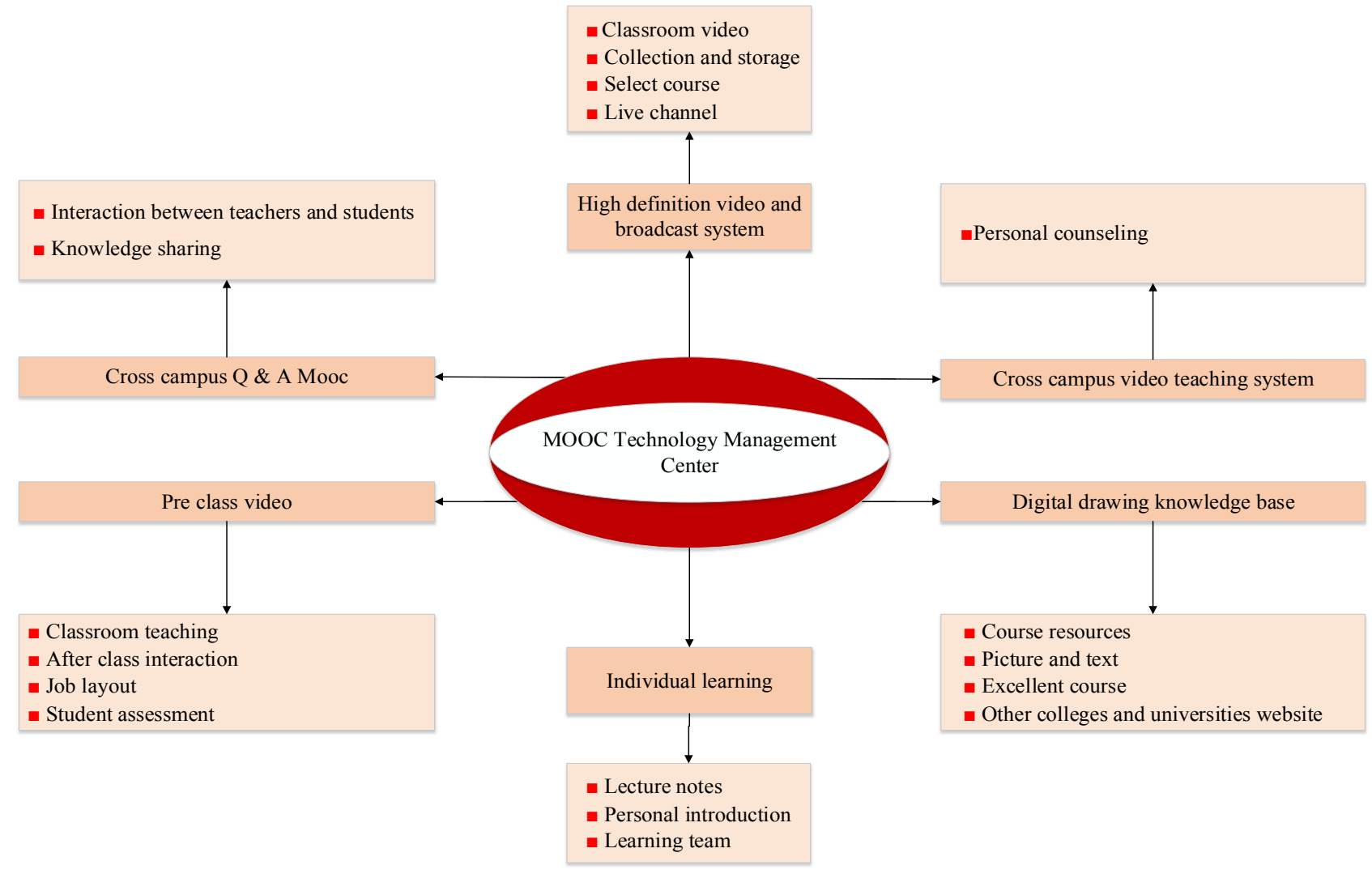

Figure 2. Design structure of distance education mode teaching based on MOOC

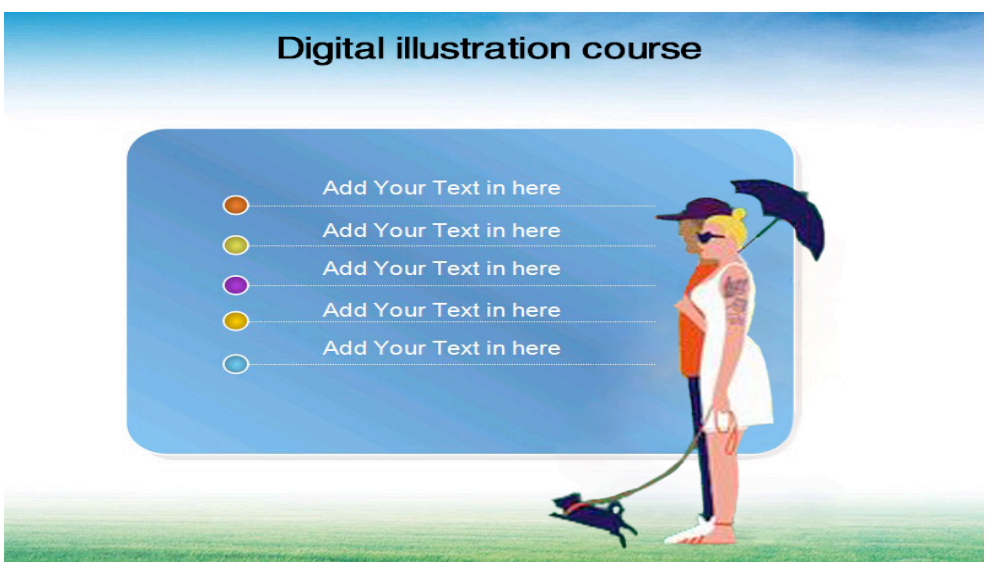

Figure 3. Mode of applying the MOOC-based distance education mode in Digital Illustration

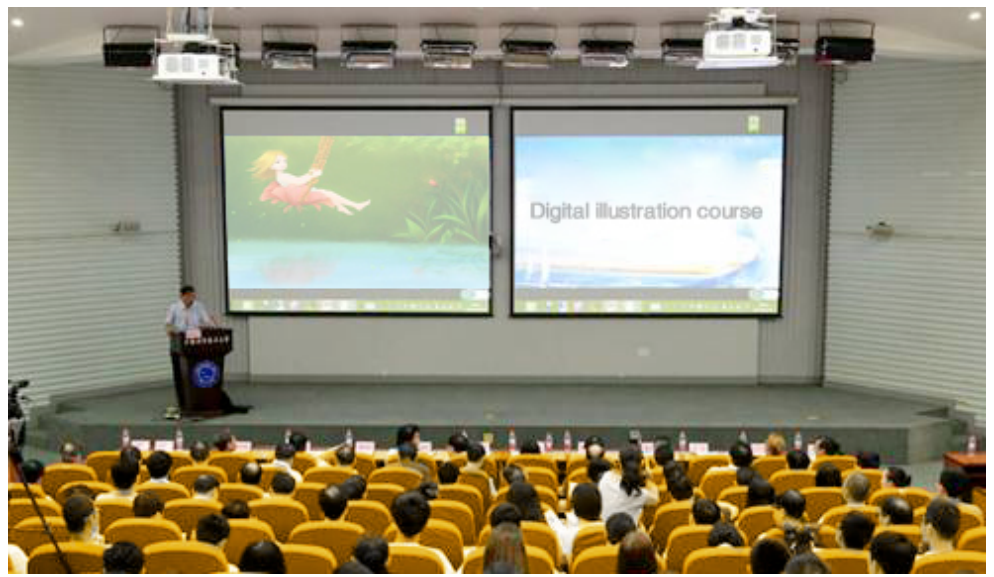

Figure 4. Mode of applying the MOOC-based distance education mode in Digital Illustration 


\section{A. Objects of study}

Digital Illustration, covering 34 class hours, was chosen as the experimental course. Objects of the experiment were sophomores majoring in Digital Illustration. 2 classes were chosen at random from 5 classes to participate in the experiment, with 40 students in each class. One class served as the experimental group which learned the course of Digital Illustration with the MOOCbased distance education mode. The other class served as the control group which was taught with the traditional online learning platform. Both classes had no significant difference in the teacher and teaching conditions, as well asthe age, gender, physical quality and comprehensive ability of students. The experiment was based on cooperation of the researchers and the practitioners. Learning and assessment contents included theory and practice. Moreover, a questionnaire developed by the teaching and research office was applied to survey and compare students in both groups.

\section{B. Research methods}

1) Control experiment method and Document literature method

The control experiment was designed to explore the effect of applying the MOOC-based distance education mode in Digital Illustration teaching. The control group took the course through the traditional online learning platform, for which the classroom mode and the single examination mode remained unchanged. The experimental group attended the course according to designed steps in the MOOC-based distance education mode.

\section{2) Mathematical statistics method}

Microsoft Excel 2010 software was used to gather and sort experimental data. Besides, SPSS13.0 statistical software was applied to analyze experimental data and to generate experimental results.

\section{Experimental design}

The progress of course teaching by the same teacher followed the order of theory teaching, practical ability and comprehensive ability. Theory teaching covered understanding of basic concepts, mastery of basic analysis methods and comprehension of relevant theories with a total of 16 class hours. Before class, students in the experimental class viewed the video as required by the teacher, actively finished extracurricular expansion tasks after class and exchanged through the MOOC platform.

The experimental results were obtained through the questionnaire survey and final examination. In the middle and at the end of the semester, students should fill in the questionnaire according to theri actual situation to ensure accuracy of survey results. The questions contained in the questionnaire involved frequency of applying functions of the platform, timeliness of viewing information, effect of before-class videos, satisfaction with the MOOC platform and adaption to the distance education mode, etc. Final examination scores were used to evaluate teaching effect and the examination consisted of three parts: basic knowledge examination, practical operation and comprehensive ability test. Each part was conducted separately, with the full score of 100 respetively. To guarantee independence of examination results, the final examination was graded by other teachers rather than the teacher of the course.

\section{Results}

This paper explored the effect of applying the MOOCbased distance education mode in Digital Illustration teaching from two aspects: questionnaire survey results and statistical data of final scores.

\section{1) Analysis of questionnaire survey results}

After short-term learning, the MOOC platform played a great role in distance education of Digital Illustration. Learning initiative of students in the experimental group was improved significantly, and their degree of participation in cases and projects was much higher. students in the experimental group were satisfied with the MOOC platform and distance education mode, with the degree of satisfaction as high as $85 \%$. Statistical results of the questionnaire survey about application of the MOOCbased distance education mode are shown in Table 1.

The survey indicates that students generally consider the application of rge MOOC-based distance education mode in Digital Illustration has a significant teaching effect ; due to access to more practice opportunities, students can achieve obvious achievement of their practical ability. Students use before-class videos most frequently. Few students are keenly interested in afterclass interaction. $80 \%$ of students can view information released by the teacher on the platform within 1-2 days. It is more convenient for students to engage in more interactive exchanges, get rich resources andinformation, thereby improve their learning effect significantly.

However, some students do not adapt to the MOOCbased distance education mode. They consider that beforeclass videos are not quite effective and quality of videos is low. In the aspect of frequency of applying fuctions of the platform, the extracurricular expansion function fails to reach the design requirement. Hence, enriching resources is still the key to promoting the MOOC platform. In final examination, performance of the experimental class is significantly superior to that of the control group. The average score is $81.65 \pm 7.82$ for the experimental class, $75.42 \pm 7.45$ for the control class-. As for the basic knowl-

TABLE I.

QUESTIONNAIRE SURVEY STATISTICS ABOUT THE APPLICATION OF MOOC-BASED DISTANCE EDUCATION MODE

\begin{tabular}{|l|l|}
\hline \multicolumn{1}{|c|}{ Question } & \multicolumn{1}{c|}{ Survey results } \\
\hline Frequency of applying functions of the platform & Before-class videos (78\%), after-class interactions (17\%), extracurricular expansion (5\%) \\
\hline Timeliness of viewing information & Within 1 day $(24 \%), 1-2$ days $(56 \%)$, more than 2 days $(20 \%)$ \\
\hline Effect of before-class videos & Good $(65 \%)$, general $(20 \%)$, ineffective $(15 \%)$ \\
\hline Satisfaction with the MOOC platform & $\begin{array}{l}\text { Learning effect }(82 \%), \text { interactive exchange }(89 \%), \text { operation easiness }(85 \%), \text { extracurricular } \\
\text { expansion }(86 \%), \text { learning mode }(84 \%)\end{array}$ \\
\hline Adaption to the distance education mode & Quite fit $(34 \%)$, fit $(45 \%)$, somewhat not fit $(11 \%)$, not fit $(10 \%)$ \\
\hline
\end{tabular}


edge module, performance of the experimental group is slightly better than that of the control group. In terms of practical ability and comprehensive ability, the experimental group has significant advantages. Thus, the experiment demonstrates the significant effect of applying the MOOC-based distance education mode in Digital Illustration teaching, especially in increasing final examination scores of students by a large margin.

\section{CONCLUSION}

It is practically proved that the MOOC-based distance education mode conforms to the teaching demand of Digital Illustration and other majors and brings a significant application effect. Compared with previous teaching modes, the MOOC-based distance education mode is richer in its teaching forms. Students can acquire more superior resources and greatly improve their learning efficiency. In addition, during making MOCC in this study, independent chapters of knowledge points were chosen from teaching resources first. Then, through incidence relation between knowledge point chapters and knowledge points, they were uploaded to the MOCC platform together with classroom video resources to prevent students from viewing unrelated contents and to further improve their learning efficiency.

Since the development of MOOC platform is still in the initial stage, it is very urgent to develop learning resources and optimize teacher resources. Continuous enrichment of learning resources will lead to expansion of learners' learning breadth. The precondition for effective implementation of the MOOC-based distance education mode is closely related to the MOOC resource library. The value of MOOC platform can be better exerted only through continuously expanding superior teaching resources and improving course resource networks. Furthermore, students' low adaption to the MOOC-based distance education mode cannot be ignored. Cultivation of students' habit of independent study online and adaption to participative teaching are also the foundation for extensive application of the MOOC-based distance education mode. Students can share learning experience through social networks, and teachers can establish interactive teaching space, so that both parties can gradually adapt to such a new teaching mode and improve teaching quality.

\section{REFERENCES}

[1] Griesbaum J., "Students as Teachers in MOOCs? The Double Gain of MOOCs as an in-Class Teaching Method Experiences from a Student-Made MOOC Online Data Privacy," International Journal of Information \& Education Technology, vol. 4, no. 1, pp. 29-34, February 2014. http://dx.doi.org/10.7763/IJIET.2014. $\underline{\mathrm{V} 4.363}$

[2] Bruff D.O., Fisher D.H., McEwen K.E., et al., "Wrapping a MOOC: Student perceptions of an experiment in blended learning," Journal of Online Learning and Teaching, vol. 9, no. 2, pp. 187-199, June 2013.

[3] Wainer A.L., Ingersoll B.R., "Disseminating ASD interventions: A pilot study of a distance learning program for parents and professionals," Journal of autism and developmental disorders, vol. 43, no. 1, pp. 11-24, January 2013. http://dx.doi.org/10.1007/ s10803-012-1538-4

[4] Carlson E.S., "Representation and Structure Conflict in the Digital Age Reassessing Archaeological Illustration and the Use of Cubist Techniques in Depicting Images of the Past," Advances in Archaeological Practice, vol. 2, no. 4, pp. 269-284, November 2014. http://dx.doi.org/10.7183/2326-3768.2.4.269

[5] Daelen A.V., Ferreira I., Marot L., et al., “A Digital Dermoscopy Follow-up Illustration and a Histopathologic Correlation for Angulated Lines in Extrafacial Lentigo Maligna," JAMA dermatology, vol. 152, no. 2, pp. 200-203, February 2016. http://dx.doi.org/10.1001/jamadermatol.2015.4132

[6] Chen X., Gao M., "MOOC course mode and its influence on colleges," Software Guide, vol. 13, no. 1, pp. 12-15, January 2014.

[7] Liao Y., "Study on network teaching mode based on MOOC idea," Information System Engineering, vol. 22, no. 7, pp. 145147, July 2015.

[8] Wang H.R., Zhang W., "Design philosophy and enlightenment of foreign large-scale open education resources - experience study on MOOC courses based on Coursera platform," Journal of Tianjin Radio and Television University, vol. 17, no. 3, pp. 32-36, September 2013.

[9] Ross J., Sinclair C., Knox J., et al., "Teacher experiences and academic identity: The missing components of MOOC pedagogy," Journal of Online Learning and Teaching, vol. 10, no. 1, pp. 57-69, March 2014.

[10] Knox J., "Digital culture clash:"massive" education in the Elearning and Digital Cultures MOOC," Distance Education, vol. 35 , no. 2, pp. 164-177, July 2014. http://dx.doi.org/10.1080/0158 7919.2014.917704

\section{AUTHORS}

Mei Zou is a lecturer in Huaihua University, Art institute of design, Huaihua, China. Her research interests include Distance Education and digital illustration. (15869900748zm@sina.com)

Submitted 07 August 2016. Published as resubmitted by the author 07 September 2016. 